\title{
A Theoretical and Experimental Study of Moderate Temperature Alfa Type Stirling Engines
}

\author{
Jacek Kropiwnicki * and Mariusz Furmanek (1) \\ Department of Energy and Industrial Apparatus, Gdansk University of Technology, 80-223 Gdansk, Poland; \\ mariusz.furmanek@pg.edu.pl \\ * Correspondence: jkropiwn@pg.edu.pl
}

Received: 26 February 2020; Accepted: 27 March 2020; Published: 2 April 2020

\begin{abstract}
The Stirling engine is a device that allows conversion of thermal energy into mechanical energy with relatively high efficiency. Existing commercial designs are mainly based on the usage of high temperature heat sources, whose availability from renewable or waste heat sources is significantly lower than that of moderate temperature sources. The paper presents the results of experimental research on a prototype alpha type Stirling engine powered by a moderate temperature source of heat. Obtained results enabled calibration of the evaluated theoretical model of the Stirling engine. The model of the engine has been subsequently used for the analysis of regenerator effectiveness influenced by the charge pressure and the heating temperature. Performed study allowed to determine further development directions of the prototype engine to improve its power and efficiency. As a result of optimization, worked out design will potentially increase the indicated efficiency up to $19.5 \%$ (5.5\% prototype) and the indicated power up to $369 \mathrm{~W}$ (114 $\mathrm{W}$ prototype).
\end{abstract}

Keywords: Stirling engine; renewable energy sources; moderate temperature; adiabatic model

\section{Introduction}

Interest in systems converting thermal energy into mechanical energy and especially Stirling technology derives from the increased demand for better management of heat obtained from other processes [1-3]. In addition to the high thermal efficiency mentioned above, the Stirling design is characterized by a simple construction-no valvetrain, i.e., a small number of moving elements that can be a source of noise and vibrations, and no impact on the natural environment when the power supply is based on fuel coming from biomass, biogas, geothermal sources or solar energy [3-6]. An advantage of Stirling's design is its simple construction in comparison with internal combustion engines [7], as its parts, e.g., the piston crown, are not exposed to high temperature working gases and chemical impact because the energy conversion process takes place outside the combustion chamber [8]. The foregoing advantages ensure maintenance-free operation and reliability.

Currently, as a result of growing interest in the use of renewable energy sources to generate electricity worldwide, a series of research on Stirling engines is being processed [9-12]. Cheng et al. [13] developed and tested a beta type Stirling engine with a rhombic-drive mechanism (displacer diameter: $70 \mathrm{~mm}$, displacer swept volume: 135 c.c.). The experiments were conducted for two different working gases (air and helium) and at various charge pressures and heating temperatures. For helium, as the working gas, at a charge pressure of 8 bar and heating temperature of $850{ }^{\circ} \mathrm{C}$, the shaft power of the engine can reach $390 \mathrm{~W}$ at $1400 \mathrm{rpm}$ with $1.21 \mathrm{~kW}$ input heat transfer rate (32.2\% thermal efficiency). For air as the working gas at a charge pressure of 6 bar and a heating temperature of $650{ }^{\circ} \mathrm{C}$, the shaft power of the engine can reach $60 \mathrm{~W}$ at $700 \mathrm{rpm}$.

Gheith et al. [14] tested a gamma type Stirling engine with air as the working gas (displacer diameter $95 \mathrm{~mm}$, displacer swept volume: 850 c.c.). A maximum brake power of $355 \mathrm{~W}$ was obtained 
for a charge pressure of 8 bar and a heating temperature of $500{ }^{\circ} \mathrm{C}$ at $600 \mathrm{rpm}$. On the basis of tests and calculations performed for the heating temperature of $300^{\circ} \mathrm{C}$ the expected brake power is $150 \mathrm{~W}$.

Karabulut et al. [15] designed and manufactured a beta type Stirling engine (displacer diameter: $69 \mathrm{~mm}$, displacer swept volume: 295 c.c.) which works at relatively lower temperatures. The presented experimental results were obtained by testing the engine with air as the working gas. The hot end of the displacer cylinder was heated with an LPG flame and maintained about $200{ }^{\circ} \mathrm{C}$. The maximum power output obtained at 2.8 bars charge pressure was $52 \mathrm{~W}$ at $453 \mathrm{rpm}$. The thermal efficiency corresponding to the maximum power was determined as $15 \%$.

Kongtragool et al. [16] designed and constructed four power pistons, gamma type, low temperature, differential Stirling engine (displacer diameter: $32 \mathrm{~mm}$, displacer swept volume: 6394 c.c.). The engine performance was tested with air at an atmospheric pressure by using a gas burner as a heat source and a heating temperature of $498^{\circ} \mathrm{C}$. The engine produces the maximum shaft power of $32.7 \mathrm{~W}$ at $42.1 \mathrm{rpm}$ and a maximum brake thermal efficiency of $0.81 \%$.

Li et al. [17] developed a beta type Stirling engine with an output shaft power of several kilowatts, which could be driven by mid-high temperature waste gases (displacer diameter: $102 \mathrm{~mm}$, displacer swept volume: 462 c.c.). The engine performance was tested with helium at a charge pressure of $20 \mathrm{bar}$ and a heating temperature of app. $500{ }^{\circ} \mathrm{C}$. The maximum power output obtained was $3476 \mathrm{~W}$ at $1248 \mathrm{rpm}$. The thermal efficiency corresponding to maximum power was determined as $26 \%$.

Sripakagorn et al. [18] developed a beta type Stirling engine (displacer diameter: $74 \mathrm{~mm}$, displacer swept volume: 165 c.c.). The engine performance was tested with air as the working gas at a charge pressure of 7 bar and a heating temperature of $500{ }^{\circ} \mathrm{C}$. The shaft power of the engine can reach $95 \mathrm{~W}$ at $360 \mathrm{rpm}$ ( $9.35 \%$ thermal efficiency). Under the atmospheric pressure, the engine produces a maximum power of $3.8 \mathrm{~W}$ at $205 \mathrm{rpm}$ and $350{ }^{\circ} \mathrm{C}$.

A free piston (beta type) Stirling engine was invented by Lane and Beale [12] (displacer diameter: $0.044 \mathrm{~m}$, displacer stroke: $0.04 \mathrm{~m}$ ). The stable engine operation was obtained at the temperature range of $120-150^{\circ} \mathrm{C}$ at the heater section (initial gas pressure: $101 \mathrm{kPa}$ ). The maximum efficiency of $5.6 \%$ at $6.4 \mathrm{~Hz}$ of frequency was obtained.

Qian et al [19] carried out tests on a beta type Stirling engine powered by a mixture of fuels: poultry litter and natural gas, showing that it is possible to use moderate temperature heat sources (cylinder head temperature: $220-584^{\circ} \mathrm{C}$ ) in a commercial engine, which was designed for high temperatures heat sources. In addition, it was shown that there is a noticeable influence of the water flow rate supplying cooling system on electrical power produced by the Stirling engine. The cooling water flow rate affected indirectly the temperature of the lower heat source as well as the temperatures of block and cylinder head.

Sowale et al. [20] performed an analysis of the thermodynamic performance of a gamma type Stirling engine integrated into a micro combustor. An analysis was performed using an adiabatic model for a moderate temperature level of the heat source $\left(150-390^{\circ} \mathrm{C}\right)$, while the engine achieved a power greater than zero at $328^{\circ} \mathrm{C}$. The analysis showed that for a heating temperature of $390{ }^{\circ} \mathrm{C}$, the Stirling engine produced the highest power of $27 \mathrm{~W}$, at the thermal efficiency of $18 \%$.

Tlili et al. [21] presented a concept of an alpha type Stirling engine powered by a solar dish, which can be supplied by the moderate temperature source of heat $\left(320^{\circ} \mathrm{C}\right)$. Performed analysis concerned the influence of a dead volume on the rated power. The optimal dead volume of $370 \mathrm{~cm}^{3}$ was calculated, which corresponded to the operating frequency of $75 \mathrm{~Hz}$ and the power of $250 \mathrm{~W}$.

Stirling engines available commercially on the market are usually sold as combined heat and power units fuelled by natural gas or diesel fuel. An example of a cogeneration unit which can be supplied with energy from renewable sources, is a unit from StirlingDK (Lyngby, Denmark). The system consists of an expanded combustion chamber, a four-cylinder, two-sided alpha type Stirling engine and an electric generator enclosed in a sealed housing. This arrangement enables the engine to be supplied with the thermal energy derived from burning wood waste in the form of chips. An operational electrical efficiency of $28 \%$ is achieved at a power output of $30 \mathrm{~kW}$. For the correct operation of the device the burning gas temperature, in the combustion chamber, should not be lower than $1000^{\circ} \mathrm{C}$. 
Another example of a commercial cogeneration unit with a Stirling engine that can be supplied with energy from renewable sources, is a unit from Stirling Biopower (Ann Arbor, MI, USA). This arrangement also consists of a four cylinder, two-sided alpha type Stirling engine and an electric generator enclosed in a sealed housing. The combustion of the biomass takes place in a separate unit that heats the air supplied to the heater. For the correct operation of the device the temperature of the air supplied to the heater should not be lower than $500{ }^{\circ} \mathrm{C}$. The system is also equipped with an integrated combustion chamber, supplying flue gases to the heater. The integrated chamber can be supplied with the following gases: CNG, LPG, biogas, synthetic gas and hydrogen. Operating with gaseous fuels of energy densities $13 \mathrm{MJ} / \mathrm{Nm}^{3}$ and higher, the electrical efficiency of $29 \%$ at $38 \mathrm{~kW}$ can be achieved.

To conclude, powering a Stirling engine with renewable energy or waste heat can be efficiently applied when the heat exchange surface of the heater is significantly increased, to cover energy demand for much lower temperature (moderate) of the energy source. This solution in turn, causes an increase of the dead volume, which contributes to the reduction of the thermal efficiency of the device.

Taking these restrictions into consideration, a prototype alpha type Stirling engine has been constructed. The heater has been designed to be supplied with exhaust gas from another process at a moderate temperature. A series of tests have been performed on the prototype engine, which unfortunately indicated that the power produced by the engine is lower than the mechanical resistance in the crankshaft system. The tests have been conducted using an external source of mechanical power, which covered the difference between the mechanical resistance and the indicated power. The obtained results enabled calibration of the theoretical model of the Stirling engine, which has been used for the analysis of regenerator effectiveness influenced by the charge pressure and the temperature of the heat source. Performed study allowed to determine further development directions of the prototype engine to improve its power and efficiency.

\section{Prototype Stirling Engine Type Alpha}

The prototype alpha type Stirling engine was developed in the laboratory of Gdańsk University of Technology (Gdansk, Poland). The layout of the prototype alpha type Stirling engine is presented in Figure 1. Due to the expected increased heat exchange surface for moderate temperatures applications, the engine has been equipped with an extended heater, connected in series with the regenerator and the cooler. The heat from the cooler is removed with water. Table 1 presents the main parameters and proprieties of the prototype alpha type Stirling engine.

The engine can be driven by moderate temperature waste gases coming from the internal combustion engine (Figure 2) which can be controlled independently by the brake on the test stand. The Stirling engine performance was tested with air as the working gas at a charge pressure of 2-6 bar and a heating temperature of $300-400{ }^{\circ} \mathrm{C}$. The Stirling engine is coupled via a belt transmission with an electric motor, serving both as a starting device and as a generator.

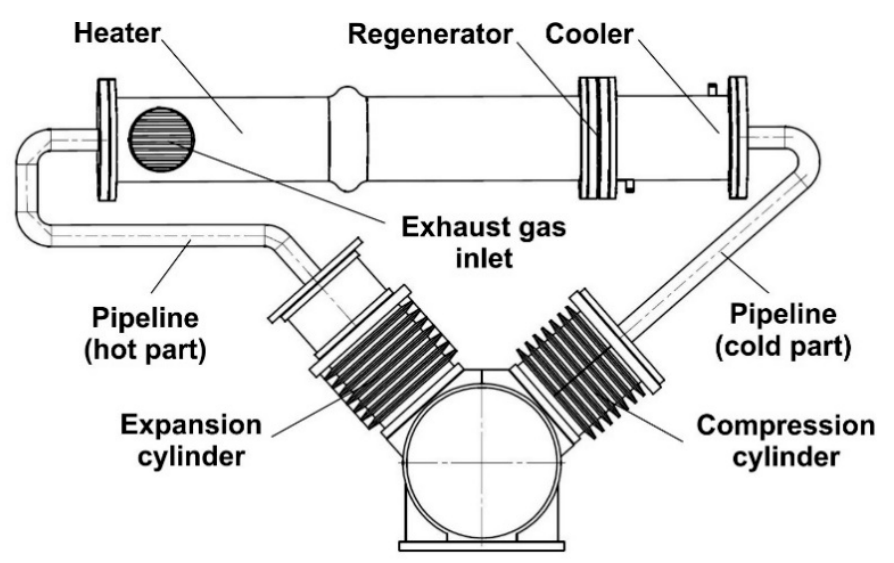

Figure 1. Layout of the prototype alpha type Stirling engine. 
Table 1. Main parameters and proprieties of the prototype alfa type Stirling engine.

\begin{tabular}{ccc}
\hline Parameter & Value & Unit \\
\hline Working gas & air & - \\
Charge pressure (bar) & $2-6$ & $\mathrm{bar}$ \\
Crankshaft rotational speed & 550 & $\mathrm{rpm}$ \\
Compression (cold) volume: swept capacity & 730 & $\mathrm{~cm}^{3}$ \\
Pipeline (cold part) & 427 & $\mathrm{~cm}^{3}$ \\
Cooler volume & 304 & $\mathrm{~cm}^{3}$ \\
Cooler exchange area & 0.46 & $\mathrm{~m}^{2}$ \\
Number of tubes in cooler & 121 & - \\
Water flow rate in cooler & $2.78 \times 10^{-3}$ & $\mathrm{~kg} / \mathrm{s}$ \\
Regenerator volume & 289 & $\mathrm{~cm}^{3}$ \\
Heater volume & 1140 & $\mathrm{~cm}^{3}$ \\
Heater exchange area & 1.71 & $\mathrm{~m}^{2}$ \\
Number of tubes in heater & 121 & - \\
Pipeline (hot part) & 427 & $\mathrm{~cm}^{3}$ \\
Expansion (hot) volume: swept capacity & 730 & $\mathrm{~cm}^{3}$ \\
\hline
\end{tabular}

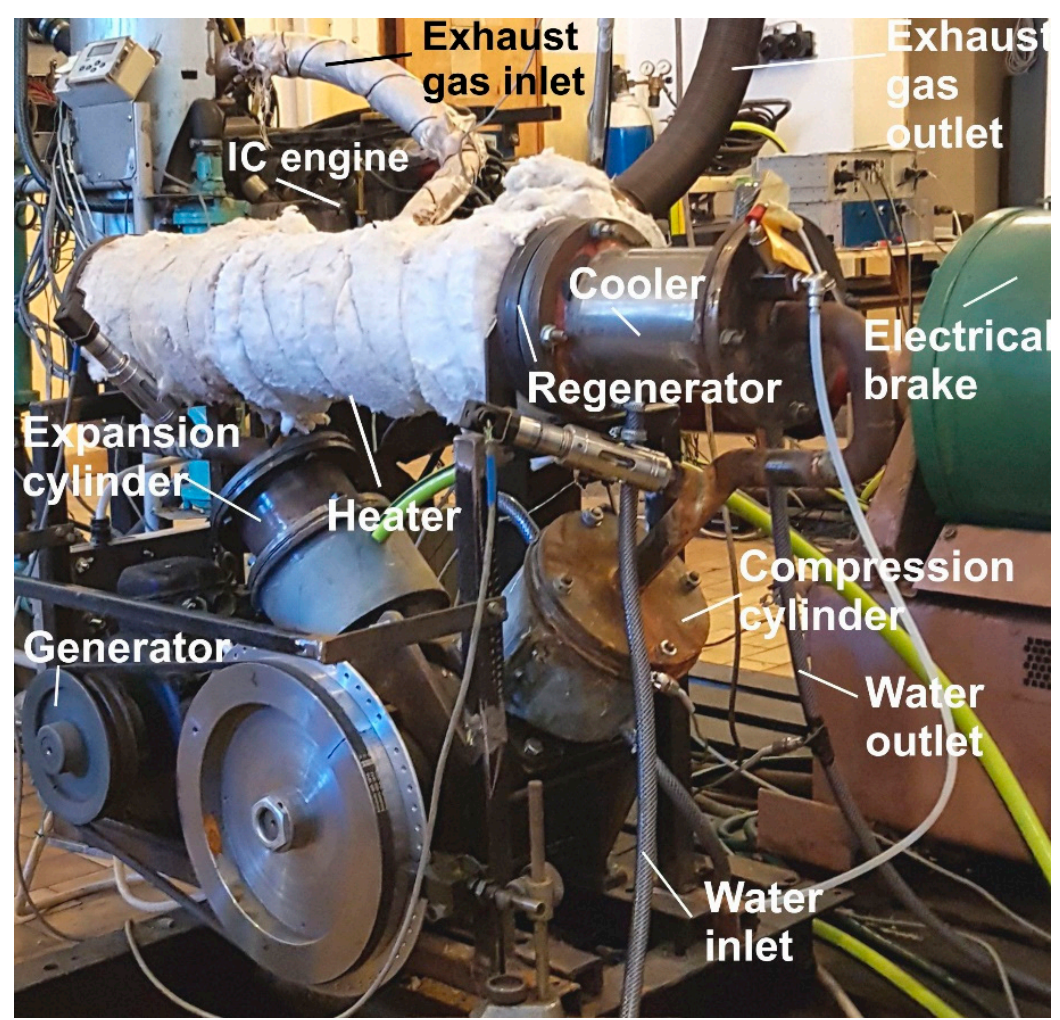

Figure 2. Test stand equipped with the prototype Stirling engine, starting motor and exhaust gas delivery system (from a spark ignition internal combustion engine).

\section{Experimental Setup and Test Procedure}

The tests were carried out at the rotational speed of $550 \mathrm{rpm}$ using an electric motor. The temperature of the exhaust gas entering and exiting the heater, as well as temperature of the cooling water, have been measured using type $\mathrm{K}$ thermocouples. The charged air is provided to the engine via a compressor with a pressure regulator. The pressure of the working gas in the Stirling engine has been measured using an NPXTG 10 sensor (Peltron, Wiazowna, Poland). The position of the crankshaft, as well as rotational speed has been measured using a position sensor. The position of the crankshaft between markers has been interpolated basing on temporary rotational speed. Data have been recorded at a frequency 
of $10 \mathrm{kHz}$ using data logger. The measurement uncertainty of apparatus used in the tests has been presented in Table 2.

Table 2. Apparatus measurement uncertainty.

\begin{tabular}{ccc}
\hline Parameter & Measurement Uncertainty & Unit \\
\hline Pressure & 2 & $\mathrm{kPa}$ \\
Temperature & 1.5 & ${ }^{\circ} \mathrm{C}$ \\
Position & 0.03 & degree \\
Rotational speed & 2 & $\mathrm{rpm}$ \\
\hline
\end{tabular}

The tests began with warming up the exhaust gas supplying the heater to the assumed temperature, then the pressure of the working medium was changed to the required value using a compressor, finally operating conditions were recorded. Temperature and flow rate of the exhaust gas have been controlled by operating point (speed, torque) of the internal combustion (IC) engine, using an electrical brake connected to the IC engine (Figure 2). Regulation of the IC engine took place by means of exhaust gas temperature, which then flowed to the heater of the Stirling engine. Regulation of the IC engine was not influenced by the Stirling engine operating parameters. Achieved accuracy of the exhaust gas temperature regulation (inlet of the heater) is $\pm 1^{\circ} \mathrm{C}$. The exhaust gas flow rate suppling the heater was calculated on the basis of the fuel consumption of the internal combustion engine and the excess air ratio. The water flow rate in the cooler has been kept constant (Table 1). The rising thermal load of the Stirling engine causes more intensive transport of the heat from the heater to the cooler via working gas, as a result temperature of water at the outflow of the cooler is also rising.

The indicated work of the engine has been calculated on the basis of the pressure course in the working space using the following formula:

$$
\mathrm{W}_{\text {ind }}=\sum_{\mathrm{i}=1}^{\mathrm{i}_{\max }}\left[\mathrm{p}_{\text {sen }_{\mathrm{i}}} \cdot\left(\Delta \mathrm{V}_{\mathrm{e}_{\mathrm{i}}}+\Delta \mathrm{V}_{\mathrm{c}_{\mathrm{i}}}\right)\right]
$$

where $p_{s e n_{i}}$ is pressure of the working gas measured by the sensor, $\Delta V_{e_{i}}$ is change of volume in the expansion cylinder, $\Delta \mathrm{V}_{\mathrm{C}_{\mathrm{i}}}$ is change of volume in the compression cylinder and $\mathrm{i}_{\max }$ is the number of samples (360 for assumed resolution 1 sample per 1 crankshaft rotation degree).

The change of volume in the compression and the expansion cylinder was determined on the basis of the system design features and the measurement of the instantaneous position of the crankshaft using the position sensor. The indicated power can be calculated using rotational speed of the crankshaft:

$$
\mathrm{P}_{\text {ind }}=\mathrm{W}_{\text {ind }} \cdot \mathrm{n}
$$

where $\mathrm{n}$ indicates the rotational speed of the crankshaft measured by the position sensor.

\section{Engine Performance}

The performed tests have been completed using air as a working gas. The prototype Stirling engine has been charged with compressed air ranging from 2 to 6 bar absolute pressure. Three levels of temperature of thermal energy source (exhaust gas from spark ignition engine) have been tested: $300,350,400{ }^{\circ} \mathrm{C}$. Recorded pressure of working gas and position of the crankshaft allowed to calculate indicated work and power of the engine. This result does not include mechanical resistance of the crankshaft system which has the crucial influence on the performance of the engine. In Figures 3 and 4 , the indicated work and power have been presented subsequently. It can been observed that depending on temperature of the thermal energy source, the optimum charge pressure is changing from 2 bar for $300{ }^{\circ} \mathrm{C}$ up to maximum tested level ( 6 bar) for $400{ }^{\circ} \mathrm{C}$. It can be concluded that further rise of charge pressure should simultaneously increase the indicated work produced by the engine for 350 as well as 
$400{ }^{\circ} \mathrm{C}$. Unfortunately, the sealing system used in the prototype engine is not suitable for such a level of pressure. The increase of the indicated work, due to heating temperature rise, is in line with the theoretical description of a Stirling engine cycle [22-24], the higher temperature difference between upper and lower heat source, the higher efficiency of the engine, which means more work for the given thermal energy impact. The effect of rising efficiency is, at the same time, amplified by the increase of thermal energy transmitted by the heater to the working gas, which comes also from the higher heating temperature. The increase of the charge pressure, on the other hand, brings a proportional increase of the mass of the working gas, which performs the work. It can be stated that the increase of the charge pressure yields a similar effect to the increase of the swept capacity. In each of the discussed situations, the increase of the indicated power is proportional to the increase of the indicated work according to the relationship (2).

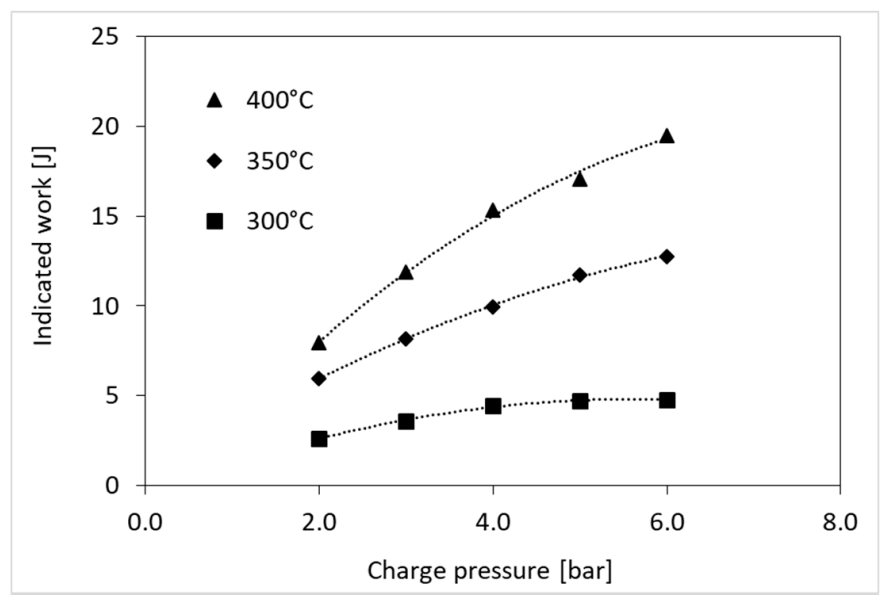

Figure 3. Experimental data of indicated work versus charge pressure of the working gas.

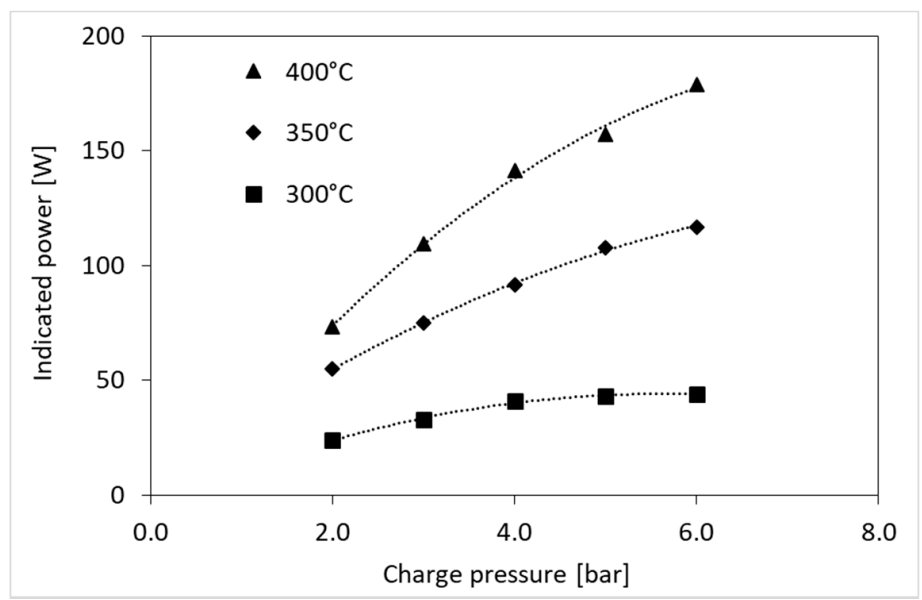

Figure 4. Experimental data of indicated power versus charge pressure of the working gas.

During the tests, it turned out that the power of the mechanical resistance of the device exceeds the power indicated in the Stirling engine and the engine is not able to work independently. The maximum indicated power of the engine is $180 \mathrm{~W}$ (Figure 4), while the mechanical resistance for this operating point was estimated at $203 \mathrm{~W}$. To start the engine autonomously, it is necessary to increase the indicated power or significantly reduce resistance, what has already been achieved by changing the sealing and lubrication system.

In Figure 5, the rate of thermal energy delivered to the engine has been analysed. For each assumed temperature of thermal energy source the delivered energy rate is constant despite the changing Stirling 
engine charge pressure. The change of rate of delivered thermal energy follows approximately linearly the change of temperature. It should be mentioned that the thermal energy is delivered by internal combustion engine and the increase in rate of thermal energy resulted from both the increase in temperature and the mass flow rate of the exhaust gas, which practically meant an increase in the torque of the internal combustion engine driving the brake.

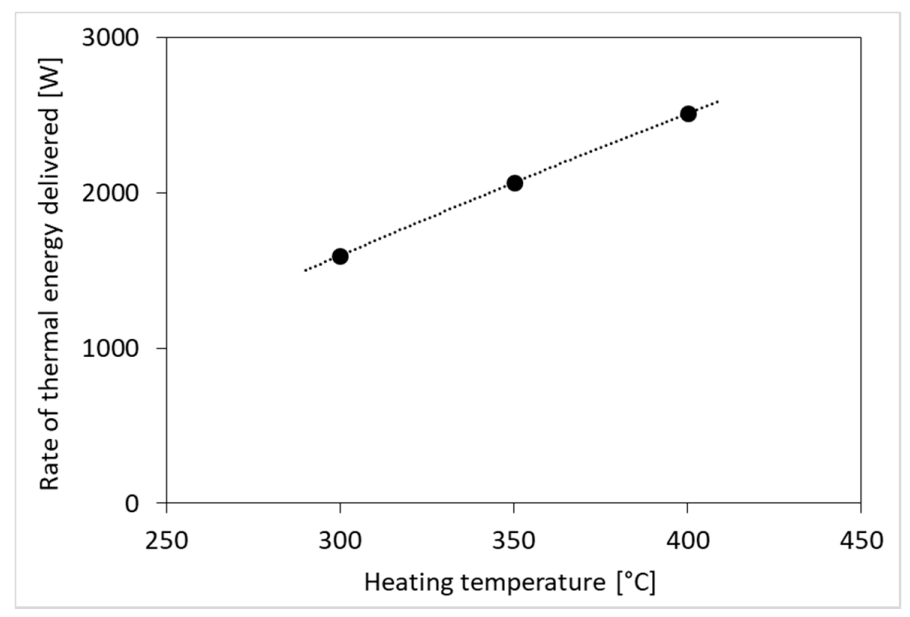

Figure 5. Experimental data of rate of thermal energy delivered versus heating temperature.

Obtained indicated efficiency of the Stirling engine has been shown in Figure 6. Like in the case of the analysed indicated work, depending on temperature of the thermal energy source, the optimum charge pressure is changing from 5 bar for $300^{\circ} \mathrm{C}$ up to maximum tested level (6 bar) for $400{ }^{\circ} \mathrm{C}$. It can be concluded that further rise of charge pressure should simultaneously rise up the indicated efficiency produced by the engine for 350 as well as $400{ }^{\circ} \mathrm{C}$.

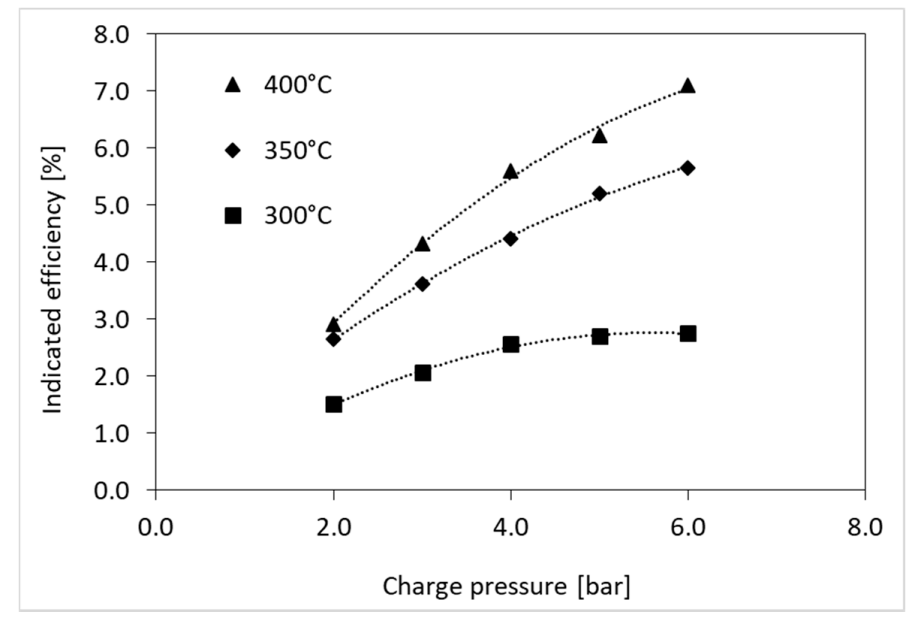

Figure 6. Experimental data of indicated efficiency versus charge pressure of the working gas.

The relatively low indicated efficiency obtained by the prototype engine is related to the low level of applied temperatures and high hydraulic resistance [25], occurring in all working elements. In addition, the construction of the heater and cooler adds a relatively large dead volume to the working space of the engine. The total ratio of dead space to the swept volume is now 2.5 and should be lowered significantly to increase the engine efficiency. For this purpose, it is necessary to increase the number of tubes in the heat exchangers and reduce the internal diameter of the tubes.

In order to optimize the presented structure of the engine, due to the achieved efficiency, the theoretical model of the engine was developed for the assumed moderate level of temperatures. 
The model has been calibrated on the basis of experimental results presented in this section. The description of the theoretical model used in the research is given in the next section.

\section{Theoretical Model of the Stirling Engine}

The alpha type Stirling engine (Figure 7) is composed of two cylinders (expansion space E and compression space $\mathrm{C}$ ), the regenerator that forms the space between the cylinders and the buffer space (under the pistons) [8]. Heat from an energy source is supplied to the expansion space via heat exchanger [26-28], whereas the heat from the compression space is removed at a lower temperature than the heat supplied to the expansion space. There is working gas in the working space and in the buffer space.

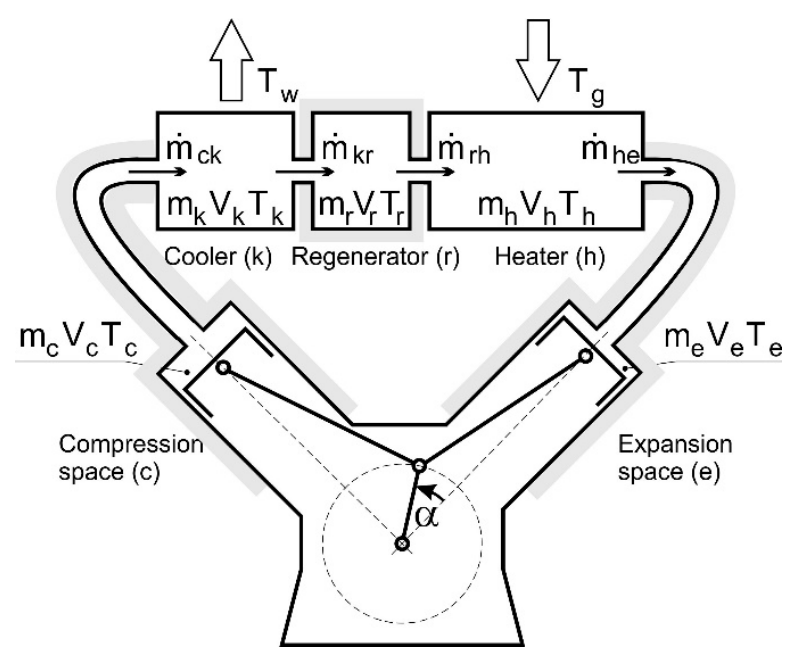

Figure 7. The Stirling engine type alfa functional scheme.

The theoretical Stirling cycle is a highly idealized thermodynamic cycle [22,29], therefore, its use is not recommended for quantitative analyses [20,30]. For practical analyses, the isothermal or adiabatic model [23,31-34] is most often used, which allows the functional separation of engine working spaces into: compression space, cooler, regenerator, heater and expansion space. Unfortunately. Basing on the fundamental assumptions for the isothermal model the temperature of the gas in compression and expansion space is constant (as well as in each distinguished space). This implies that those exchangers are useless and the whole heat exchange process takes place in the compression and expansion space only. Obviously, this cannot be correct, since the cylinder walls are not able to cover the expected heat demand. The analysis was conducted using adiabatic model with the assumption that there is no heat exchange with environment in: the compression space, the regenerator, the expansion space and in adjacent pipelines.

The starting point of the analysis is that the instantaneous pressure in each element of the Stirling engine is the same for the pointed crankshaft position. The total mass of gas in the machine is constant, thus:

$$
\dot{\mathrm{m}}_{\mathrm{c}}+\dot{\mathrm{m}}_{\mathrm{k}}+\dot{\mathrm{m}}_{\mathrm{r}}+\dot{\mathrm{m}}_{\mathrm{h}}+\dot{\mathrm{m}}_{\mathrm{e}}=0
$$

where $\dot{m}_{x}$ defines mass accumulation speed of the working gas in the space $x$ (index $x$ specification in Figure 7).

Assuming that the conditions $\dot{\mathrm{W}}_{\mathrm{k}}=0$ and $\dot{\mathrm{V}}_{\mathrm{k}}=0$ are met for the heat exchanger we obtain for the cooler:

$$
\dot{\mathrm{Q}}_{\mathrm{k}}=\frac{\mathrm{c}_{\mathrm{v}}}{\mathrm{R}} \cdot \dot{\mathrm{p}} \cdot \mathrm{V}_{\mathrm{k}}-\left(\mathrm{c}_{\mathrm{p}} \cdot \dot{\mathrm{m}}_{\mathrm{ck}} \cdot \mathrm{T}_{\mathrm{ck}}-\mathrm{c}_{\mathrm{p}} \cdot \dot{\mathrm{m}}_{\mathrm{kr}} \cdot \mathrm{T}_{\mathrm{kr}}\right)
$$


Similarly, for the regenerator and the heater we obtain respectively:

$$
\begin{aligned}
& \dot{\mathrm{Q}}_{\mathrm{r}}=\frac{\mathrm{c}_{\mathrm{V}}}{\mathrm{R}} \cdot \dot{\mathrm{p}} \cdot \mathrm{V}_{\mathrm{r}}-\left(\mathrm{c}_{\mathrm{p}} \cdot \dot{\mathrm{m}}_{\mathrm{kr}} \cdot \mathrm{T}_{\mathrm{kr}}-\mathrm{c}_{\mathrm{p}} \cdot \dot{\mathrm{m}}_{\mathrm{rh}} \cdot \mathrm{T}_{\mathrm{rh}}\right) \\
& \dot{\mathrm{Q}}_{\mathrm{h}}=\frac{\mathrm{c}_{\mathrm{V}}}{\mathrm{R}} \cdot \dot{\mathrm{p}} \cdot \mathrm{V}_{\mathrm{h}}-\left(\mathrm{c}_{\mathrm{p}} \cdot \dot{\mathrm{m}}_{\mathrm{rh}} \cdot \mathrm{T}_{\mathrm{rh}}-\mathrm{c}_{\mathrm{p}} \cdot \dot{\mathrm{m}}_{\mathrm{he}} \cdot \mathrm{T}_{\mathrm{he}}\right)
\end{aligned}
$$

The pressure of the working gas can be calculated using the following formula:

$$
\dot{\mathrm{p}}=-\mathrm{p} \cdot \mathrm{k} \cdot \frac{\left(\frac{\dot{\mathrm{V}}_{\mathrm{c}}}{\mathrm{T}_{\mathrm{ck}}}+\frac{\dot{\mathrm{V}}_{\mathrm{e}}}{\mathrm{T}_{\mathrm{he}}}\right)}{\frac{\mathrm{V}_{\mathrm{c}}}{\mathrm{T}_{\mathrm{ck}}}+\frac{\mathrm{V}_{\mathrm{e}}}{\mathrm{T}_{\mathrm{he}}}+\kappa \cdot\left(\frac{\mathrm{V}_{\mathrm{k}}}{\mathrm{T}_{\mathrm{k}}}+\frac{\mathrm{V}_{\mathrm{r}}}{\mathrm{T}_{\mathrm{r}}}+\frac{\mathrm{V}_{\mathrm{h}}}{\mathrm{T}_{\mathrm{h}}}\right)}
$$

For the compression space the temperature can be evaluated using the formula:

$$
\dot{\mathrm{T}}_{\mathrm{c}}=\mathrm{T}_{\mathrm{c}} \cdot\left(\frac{\dot{\mathrm{p}}}{\mathrm{p}}+\frac{\dot{\mathrm{V}}_{\mathrm{c}}}{\mathrm{V}_{\mathrm{c}}}-\frac{\dot{\mathrm{m}}_{\mathrm{c}}}{\mathrm{m}_{\mathrm{c}}}\right)
$$

where:

$$
\mathrm{m}_{\mathrm{c}}=\frac{\mathrm{p} \cdot \mathrm{V}_{\mathrm{c}}}{\mathrm{T}_{\mathrm{c}} \cdot \mathrm{R}}
$$

Analogously, for the expansion space we obtain:

$$
\dot{\mathrm{T}}_{\mathrm{e}}=\mathrm{T}_{\mathrm{e}} \cdot\left(\frac{\dot{\mathrm{p}}}{\mathrm{p}}+\frac{\dot{\mathrm{V}}_{\mathrm{e}}}{\mathrm{V}_{\mathrm{e}}}-\frac{\dot{\mathrm{m}}_{\mathrm{e}}}{\mathrm{m}_{\mathrm{e}}}\right)
$$

where:

$$
\mathrm{m}_{\mathrm{e}}=\frac{\mathrm{p} \cdot \mathrm{V}_{\mathrm{e}}}{\mathrm{T}_{\mathrm{e}} \cdot \mathrm{R}}
$$

The mass flows used in earlier equations can be defined using the following relations:

$$
\left\{\begin{array}{c}
\dot{\mathrm{m}}_{\mathrm{ck}}=-\dot{\mathrm{m}}_{\mathrm{c}} \\
\dot{\mathrm{m}}_{\mathrm{kr}}=\dot{\mathrm{m}}_{\mathrm{ck}}-\dot{\mathrm{m}}_{\mathrm{k}} \\
\dot{\mathrm{m}}_{\mathrm{rh}}=\dot{\mathrm{m}}_{\mathrm{e}}+\dot{\mathrm{m}}_{\mathrm{h}} \\
\dot{\mathrm{m}}_{\mathrm{he}}=\dot{\mathrm{m}}_{\mathrm{e}}
\end{array}\right.
$$

where:

$$
\begin{gathered}
\dot{\mathrm{m}}_{\mathrm{c}}=\frac{1}{\mathrm{R} \cdot \mathrm{T}_{\mathrm{ck}}} \cdot \mathrm{p} \cdot \dot{\mathrm{V}}_{\mathrm{c}}+\frac{1}{\mathrm{~K} \cdot \mathrm{R} \cdot \mathrm{T}_{\mathrm{ck}}} \cdot \dot{\mathrm{p}} \cdot \mathrm{V}_{\mathrm{c}} \\
\dot{\mathrm{m}}_{\mathrm{k}}=\dot{\mathrm{p}} \cdot \frac{\mathrm{V}_{\mathrm{k}}}{\mathrm{R} \cdot \mathrm{T}_{\mathrm{k}}} \\
\dot{\mathrm{m}}_{\mathrm{r}}=\dot{\mathrm{p}} \cdot \frac{\mathrm{V}_{\mathrm{r}}}{\mathrm{R} \cdot \mathrm{T}_{\mathrm{r}}} \\
\dot{\mathrm{m}}_{\mathrm{h}}=\dot{\mathrm{p}} \cdot \frac{\mathrm{V}_{\mathrm{h}}}{\mathrm{R} \cdot \mathrm{T}_{\mathrm{h}}} \\
\dot{\mathrm{m}}_{\mathrm{e}}=\frac{1}{\mathrm{R} \cdot \mathrm{T}_{\mathrm{he}}} \cdot \mathrm{p} \cdot \dot{\mathrm{V}}_{\mathrm{e}}+\frac{1}{\mathrm{~K} \cdot \mathrm{R} \cdot \mathrm{T}_{\mathrm{he}}} \cdot \dot{\mathrm{p}} \cdot \mathrm{V}_{\mathrm{e}}
\end{gathered}
$$

In the regenerator, the gas cyclically flows from the cooler to the heater and in reverse direction. The gas is respectively heated and cooled by the metal mesh placed in the regenerator. The net 
heat transfer per cycle is zero. The regenerator quality is defined by the regenerator effectiveness $\varepsilon$, the parameter that allows to calculate the regenerator temperature difference:

$$
\Delta \mathrm{T}_{\mathrm{r}}=\frac{\left(\mathrm{T}_{\mathrm{h}}-\mathrm{T}_{\mathrm{k}}\right)}{2} \cdot(1-\varepsilon)
$$

Hence, the temperature of the gas coming into the cooler from the regenerator will be higher than the temperature of gas in the cooler by $2 \varepsilon \mathrm{T}_{\mathrm{r}}$. Analogically, the gas coming into the heater from the regenerator will be cooler than temperature of gas in the heater by $2 \varepsilon \mathrm{T}_{\mathrm{r}}$.

The adiabatic work produced by the Stirling engine in the expansion and compression spaces for the whole cycle equals:

$$
\mathrm{W}_{\mathrm{ad}}=\int_{0}^{\tau_{\mathrm{c}}} \mathrm{p} \cdot\left(\dot{\mathrm{V}}_{\mathrm{c}}+\dot{\mathrm{V}}_{\mathrm{e}}\right) \cdot \mathrm{dt}
$$

The working fluid is passing heat exchangers between compression and expansion cylinders accompanied by the friction and local loss, which results in a pressure loss across all the elements. This effect reduces the net work of the engine. In this work, the total pressure loss in a system has been treated as coming from the local losses, which allowed to define the instantaneous pressure loss:

$$
\Delta \mathrm{p}=\mathrm{K}_{\mathrm{l}} \cdot \rho \cdot \frac{\mathrm{w}^{2}}{2}
$$

where $\mathrm{K}_{\mathrm{L}}$ is the loss coefficient, $\rho$ is the working gas density in the pipeline (Figure 1) and $\mathrm{w}$ is the instantaneous working gas velocity in the pipeline (Figure 1).

Based on the tests [25] performed for the analysed elements: cold pipeline, cooler, regenerator, heater, hot pipeline, the following relation has been evaluated:

$$
\mathrm{K}_{1}=28.6 \cdot \mathrm{e}^{-\left(\operatorname{Re} \cdot 5.61 \cdot 10^{-4}\right)}
$$

where Re is Reynolds number for the pipeline (Figure 1).

The pumping loss for one cycle can be then calculated as follows:

$$
\mathrm{W}_{\text {pump }}=\int_{0}^{\tau_{\mathrm{c}}} \Delta \mathrm{p} \cdot \dot{\mathrm{V}}_{\mathrm{e}} \cdot \mathrm{dt}
$$

The net adiabatic work corresponding to indicated work, is a difference of the work calculated for the evaluated pressure change (19) and the pumping loss (22):

$$
\mathrm{W}_{\mathrm{ad}}^{\text {net }}=\mathrm{W}_{\mathrm{ad}}-\mathrm{W}_{\text {pump }}
$$

The energy delivered to the engine is given by:

$$
\mathrm{Q}_{\mathrm{in}}=\int_{0}^{\tau_{\mathrm{c}}} \dot{\mathrm{Q}}_{\mathrm{h}} \cdot \mathrm{dt}
$$

The energy loss during cooling is given by:

$$
\mathrm{Q}_{\text {out }}=\int_{0}^{\tau_{\mathrm{c}}} \dot{\mathrm{Q}}_{\mathrm{k}} \cdot \mathrm{dt}
$$

The net adiabatic efficiency of the Stirling engine can be calculated using the following formula:

$$
\eta_{\text {th }}=\frac{\mathrm{W}_{\mathrm{ad}}^{\text {net }}}{\mathrm{Q}_{\mathrm{in}}}
$$


For a more realistic analysis it is convenient to define the temperature of the gas delivering heat to the Stirling engine (the waste energy) and the temperature of water receiving heat from the device instead of the temperature of working gas in the heater and the cooler, respectively [35,36]. Hence, assuming the energy is transferred with $100 \%$ efficiency through the heat exchanger, we can define the average rate of heat delivered to the working gas in the heater:

$$
\overline{\mathrm{Q}}_{\mathrm{h}}=\frac{\mathrm{Q}_{\mathrm{in}}}{\tau_{\mathrm{c}}}=\mathrm{k}_{\mathrm{g}} \cdot \mathrm{Ag}_{\mathrm{g}} \cdot\left(\mathrm{T}_{\mathrm{g}}-\mathrm{T}_{\mathrm{h}}\right)
$$

and the average rate of heat received from the working gas in the cooler:

$$
\overline{\mathrm{Q}}_{\mathrm{k}}=\frac{\mathrm{Q}_{\mathrm{out}}}{\tau_{\mathrm{c}}}=\mathrm{k}_{\mathrm{w}} \cdot \mathrm{A}_{\mathrm{w}} \cdot\left(\mathrm{T}_{\mathrm{w}}-\mathrm{T}_{\mathrm{k}}\right)
$$

The equations presented in this section are used to determine the desired parameters of the working gas, e.g., pressure, temperature in the compression space, expansion, engine efficiency, etc. Some of the variables contained in the equations can be assumed, for example, the volume of the compression space:

$$
\mathrm{V}_{\mathrm{C}}=0.5 \cdot \mathrm{V}_{\mathrm{SC} . \mathrm{c}} \cdot(1+\cos (\varphi-\alpha-\pi))
$$

and for the expansion space:

$$
\mathrm{V}_{\mathrm{e}}=0.5 \cdot \mathrm{V}_{\text {SC.e }} \cdot(1+\cos (\varphi-\pi))
$$

Other variables depend on the direction of mass flow. Hence, the temperature of the working gas coming into the cooler from the compression space can be defined using the following formula:

$$
\mathrm{T}_{\mathrm{ck}}=\left\{\begin{array}{l}
\mathrm{T}_{\mathrm{c}} \text { if } \dot{\mathrm{m}}_{\mathrm{ck}} \geq 0 \\
\mathrm{~T}_{\mathrm{k}} \text { if } \dot{\mathrm{m}}_{\mathrm{ck}}<0
\end{array}\right.
$$

Analogously, for the temperature of the working gas coming into the regenerator from the cooler we obtain:

$$
\mathrm{T}_{\mathrm{kr}}=\left\{\begin{array}{l}
\mathrm{T}_{\mathrm{k}} \text { if } \dot{\mathrm{m}}_{\mathrm{kr}} \geq 0 \\
\mathrm{~T}_{\mathrm{r}} \text { if } \dot{\mathrm{m}}_{\mathrm{kr}}<0
\end{array}\right.
$$

and for the temperature of the working gas coming into the heater from the regenerator we obtain:

$$
\mathrm{T}_{\mathrm{rh}}=\left\{\begin{array}{l}
\mathrm{T}_{\mathrm{r}} \text { if } \dot{\mathrm{m}}_{\mathrm{rh}} \geq 0 \\
\mathrm{~T}_{\mathrm{h}} \text { if } \dot{\mathrm{m}}_{\mathrm{rh}}<0
\end{array}\right.
$$

while for the temperature of the working gas coming into the expansion space from the heater we obtain:

$$
\mathrm{T}_{\mathrm{he}}=\left\{\begin{array}{l}
\mathrm{T}_{\mathrm{h}} \text { if } \dot{\mathrm{m}}_{\mathrm{he}} \geq 0 \\
\mathrm{~T}_{\mathrm{e}} \text { if } \dot{\mathrm{m}}_{\mathrm{he}}<0
\end{array}\right.
$$

If the initial values of variables are not known, e.g., pressure, the temperature in the compression and expansion space, etc. we need to use iterative procedure for calculations (Figure 8). In such a procedure, we assume that the cycle is of a repetitive nature, which means that the calculations can be completed when respective values at the beginning and the end of the cycle are the same, e.g., the temperature of the working gas in the compression space. Hence, the results of the calculations for one cycle of work are used as initial conditions in the next iteration. In the iterative procedure, the initial pressure and temperature values in all control volumes are assumed, as well as the temperature of the exhaust gas supplying heat to the engine and the temperature of the cooling water. In the first calculation step, the direction of the working gas flow in the Stirling engine is determined on the basis of the volume change balance in the expansion and compression space, hence the initial values of the gas stream and its temperature between control volumes are calculated. In the next steps, only the results from the 
previous calculation steps are taken into account. After each calculation step, the indicated work is calculated alongside with the amount of heat supplied, removed and accumulated by the regenerator. The convergence was controlled by the conformity of the compression and expansion temperatures at the end of one cycle and the beginning of the next one, as well as by the energy balance released and absorbed in the regenerator, which should equal zero.



Figure 8. Schematic drawing of the calculations steps using the adiabatic model.

\section{Results and Discussion}

On the basis of the test results of the Stirling engine prototype, the model was calibrated, taking as its input the prototype's geometric and design features, charge pressure, heating temperature, cooling water temperature, heat transfer coefficients for the heater and cooler, as well as the loss coefficient function (21), which defines pumping loss.

The calibration has been performed assuming that the average value of the indicated work, for the considered operating points, cannot differ for model and experimental data by more than $1 \%$.

Figures 9-11 present the results of comparison of the indicated work obtained from the experiment and the adiabatic model (pumping loss included). As a result of the calibration, regenerator effectiveness characteristics has been obtained, which was the last missing data in the model. Due to the high uniqueness of the regenerator designs used in prototype solutions [24,37,38], this is a much more accurate method of determining its characteristics than the use of experimental formulas worked out for similar constructions. 




Figure 9. Comparison of indicated work calculated on the basis of experiment and adiabatic models (pumping loss included) for heating temperature of $300^{\circ} \mathrm{C}$.

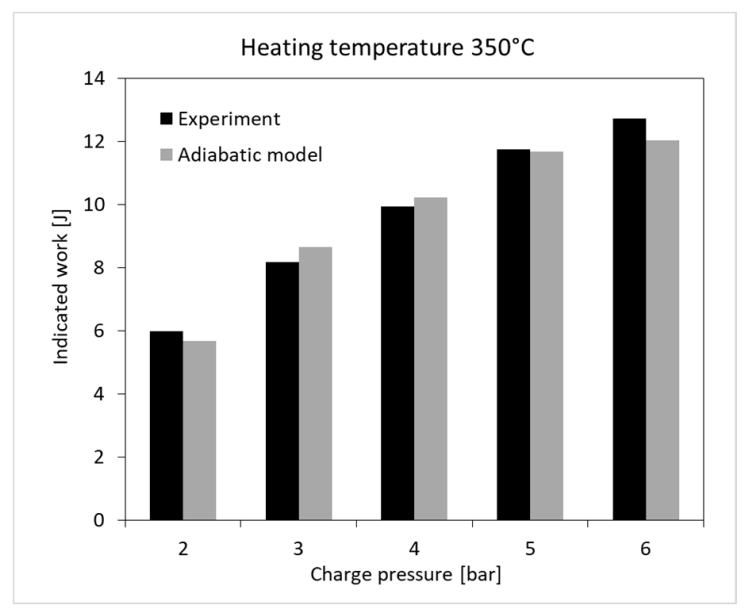

Figure 10. Comparison of indicated work calculated on the basis of experiment and adiabatic model (pumping loss included) for heating temperature of $350{ }^{\circ} \mathrm{C}$.

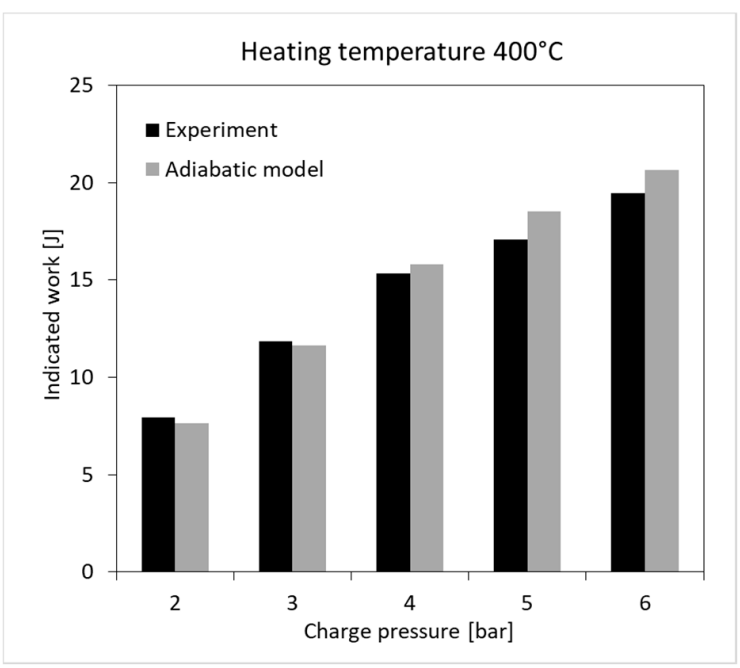

Figure 11. Comparison of indicated work calculated on the basis of experiment and adiabatic model (pumping loss included) for heating temperature of $400{ }^{\circ} \mathrm{C}$. 
Figure 12 shows the regenerator effectiveness characteristics evaluated during the model calibration. Based on the obtained results, it can be concluded that in the tested temperature range the regenerator effectiveness is not explicitly related to this parameter. In the pressure range above 4 bar it can be seen that the increase in temperature also increases the efficiency but for pressures below 3 bar the regenerator effectiveness is higher at a temperature of $350{ }^{\circ} \mathrm{C}$ rather than $400{ }^{\circ} \mathrm{C}$. Similar results were obtained in [37], where also the general tendency of the regenerator effectiveness rise due to temperature is not always maintained and these changes occur in a similar range $( \pm 5 \%$ change in efficiency for temperature changes by $100{ }^{\circ} \mathrm{C}$ ). In the case of rising charge pressure, a general tendency to increase regenerator effectiveness was observed, regardless of the heating temperature. In the work [37] a similar pattern was found.



Figure 12. Influence of charge pressure and heating temperature on regenerator effectiveness.

For further considerations regarding the impact of selected design features of the system on the efficiency and power, the authors decided to use the simplified characteristics of the regenerator effectiveness taking into account only the effect of charge pressure:

$$
\varepsilon=3.33 \cdot \mathrm{p}_{\mathrm{ch}}+39.3
$$

Using the calibrated adiabatic model of the Stirling prototype engine, the effect of dead heater and radiator volume on the efficiency and the power of the prototype engine was determined.

It was assumed that main structural features of the analysed engine were retained (Table 1), only the dimensions of the heater and cooler (heat exchange surface and volume occupied by the working gas) were changed. For the original prototype engine configuration, at the heating temperature of $350^{\circ} \mathrm{C}$ and the charge pressure of 6 bar, calculations of the temperatures in the selected spaces of the engine have been performed (Figures 13 and 14), as well as the calculations of the pressure of the working gas (Figure 15).

According to the assumptions of the adiabatic model, temperatures in heater, regenerator and cooler are constant, while in elements where the process is adiabatic i.e., expansion and compression space, the course of temperature has a sinusoidal profile (Figure 13). However, at the boundaries of the control spaces, depending on the instantaneous flow direction, a rapid temperature change occurs (Figure 14). For example, between the heater - expansion spaces, during the flow from the expansion space the temperature is lower, and during the flow from the heater, the temperature is higher and corresponds to that in the heater. On this basis, the adiabatic work has been calculated (19) and, after taking pumping loss (22) into account the net adiabatic work (23) has been also calculated.

Next, the numerical optimization of the heat exchange surface in the heater and cooler has been performed due to charge pressure (Figure 16) and regenerator effectiveness (Figure 17). The changing the heat exchange surface resulted in a proportional change in the dead volume in the space of the heater and cooler. The simulations have been carried out for the heating temperature of $350^{\circ} \mathrm{C}$. 


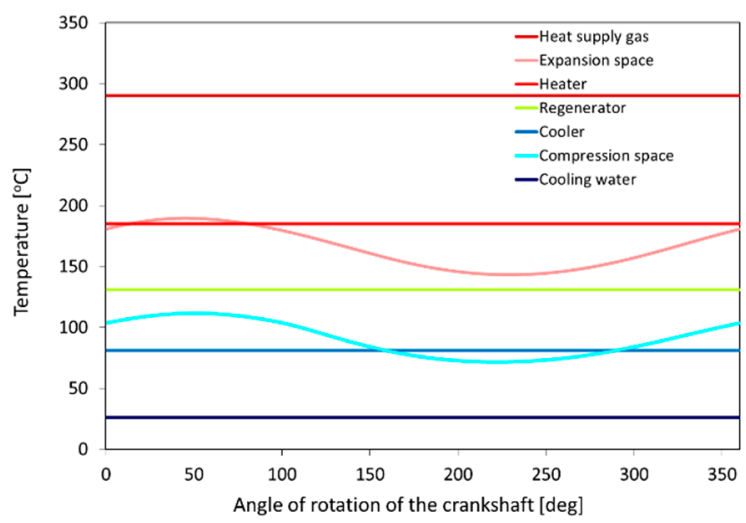

Figure 13. Temperatures distribution in controlled spaces for one cycle; charge pressure 6 bar; regenerator effectiveness $60 \%$.

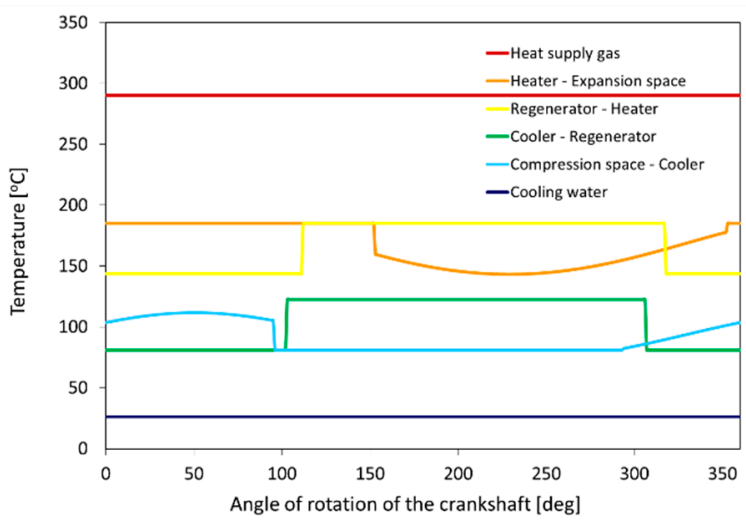

Figure 14. Temperatures distribution between controlled spaces for one cycle; charge pressure 6 bar; regenerator effectiveness $60 \%$.

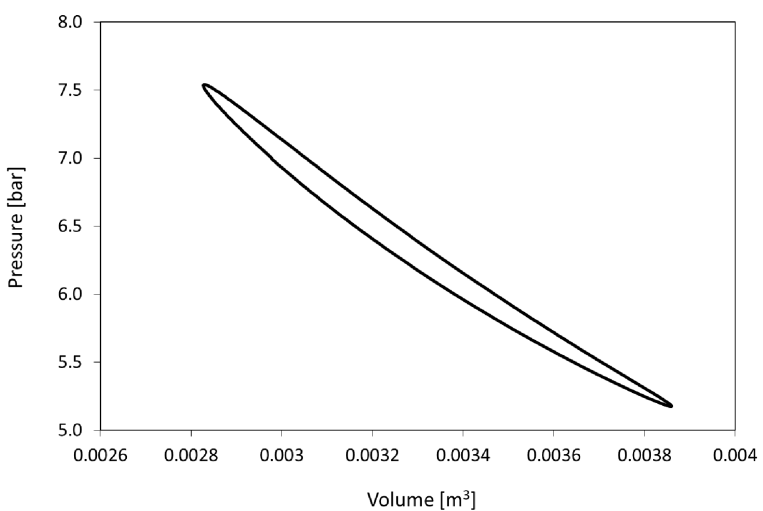

Figure 15. Volume-pressure diagram; charge pressure 6 bar; regenerator effectiveness $60 \%$; heating temperature $350{ }^{\circ} \mathrm{C}$.

On the basis of the results (Figure 16), it can be stated that the engine power increases along with the charge pressure, which is caused by the increase in the amount of the gas performing the work. However, this is not accompanied by a significant increase in the flow velocity, which is associated with hydraulic resistance. The engine efficiency reaches approximately the maximum value also at 6 bar pressure, while further increase is limited due to the imperfection of the adiabatic model describing the process. In this model, it is assumed that the temperature in the heater and cooler is constant, which means that it is necessary to bring or remove huge amounts of heat, when the expansion or the 
compression is underway in the working space. Further increase of the charge pressure, therefore, causes a proportional increase in the mass of the working gas, and in the consequence of the model's operation, an increased amount of heat input and increased dimensions of heat exchangers and the dead space. Especially the last factor has a negative impact on the engine efficiency. The impact of charge pressure on engine efficiency is not determined by the adiabatic model in a sufficiently accurate manner and requires refinement. In a real engine, the processes of heat supply and dissipation are not isothermal and this disruption needs to be corrected by refining the Stirling engine model allowing non-isothermal way of these processes.

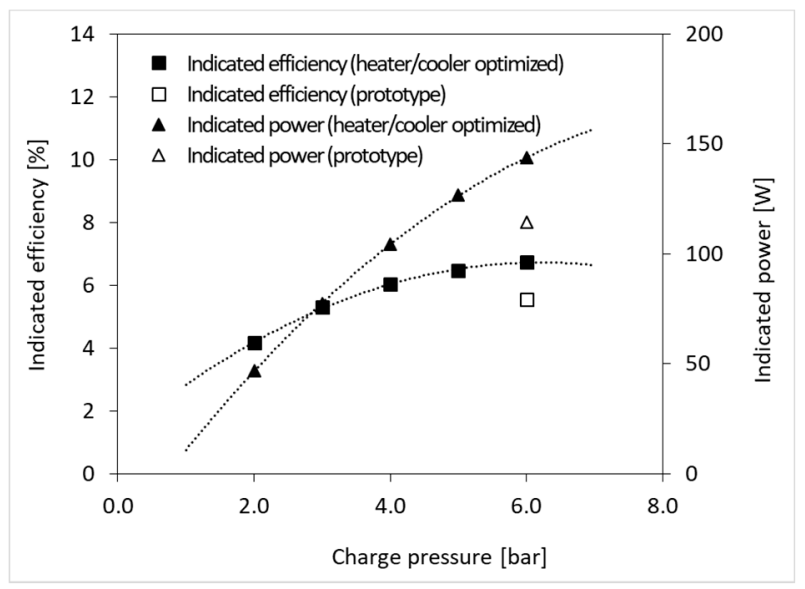

Figure 16. Influence of charge pressure on efficiency and indicated power of the Stirling engine; heating temperature $350{ }^{\circ} \mathrm{C}$, regenerator effectiveness $60 \%$.

Based on the results presented in Figure 17 it can be concluded that engine power and efficiency increase relatively quickly with regenerator effectiveness. This is the result of an increasing amount of heat that is delivered from the regenerator during the expansion process, and thus a reduction of the amount of heat that must be supplied from the outside.

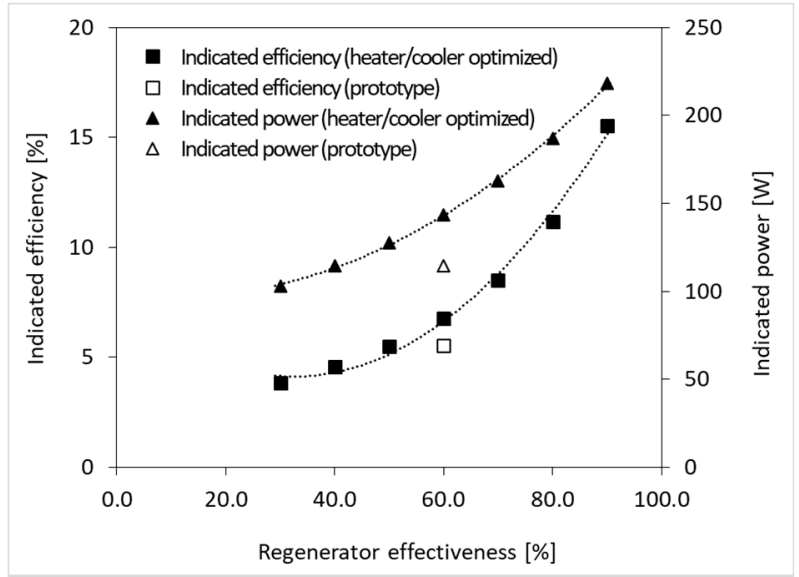

Figure 17. Influence of regenerator effectiveness on efficiency and indicated power of the Stirling engine; heating temperature $350^{\circ} \mathrm{C}$, charge pressure 6 bar.

The results presented in Figures 16 and 17 both show that it is possible to significantly increase the efficiency and power of the engine by optimizing the heat exchange surface of the heater and cooler. The result of this process, however, depends on the operating parameters of the engine, so it must be repeated when the heating temperature or the charge pressure has been changed. 
Figure 18 presents a summary of the simulation results obtained for three cases of the Stirling engine configuration: (1) the original ones used in the prototype, (2) for the optimized design of the heater and cooler and (3) with increased regenerator effectiveness up to $90 \%$ (design modification).

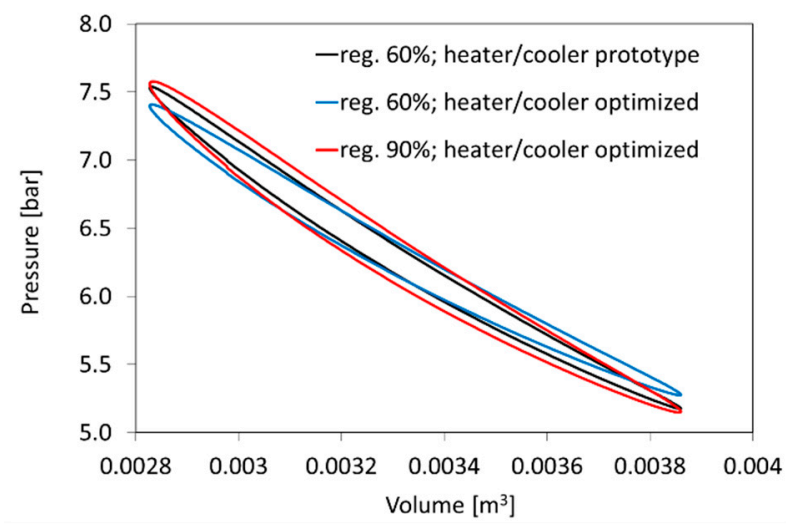

Figure 18. Volume-pressure diagram for different values of regenerator effectiveness and heater/cooler size; heating temperature $350^{\circ} \mathrm{C}$, charge pressure 6 bar.

In case 1 the design parameters at which the engine prototype was tested are used (they are presented in Table 1, regenerator efficiency $60 \%$ ). In case 2, the heat exchange surfaces in the heater and the cooler are modified, while the diameters of pipes remain the same $(4 \mathrm{~mm})$. As a result, the ratio of the heat exchange surface and the dead volume, occupied by working gas in a given exchanger, remains unchanged. The selection of the heat exchange surfaces mentioned above was optimized due to the efficiency of the engine and was performed using the numerical optimization procedure. In case 3, a structural change of the regenerator was considered, using a filling with a higher heat exchange area, while maintaining the same porosity (finer elements), to obtain a higher regenerator efficiency. At the same time, it was assumed that the heater and the cooler are made of tubes with smaller diameters $(1 \mathrm{~mm})$, their number and length were determined by the calculated heat exchange area. This solution enabled a significant reduction of dead space in regenerator. Heat exchange area in the heater and the cooler were optimized the same way as it was described in case 2 .

All cases are related to the heating temperature of $350{ }^{\circ} \mathrm{C}$ and a charge pressure of 6 bar. The introduction of these modifications leads to an increase in both engine efficiency and power output (Table 3). Especially the latest modification including the reduction of the dead space by changing the internal diameter of the tubes in heat exchangers from $4 \mathrm{~mm}$ (prototype) to $1 \mathrm{~mm}$, leads to an increase in engine power by $220 \%$ as compared to the prototype solution.

Table 3. Operating parameters of the Stirling engine for different values of regenerator effectiveness and heater/cooler size.

\begin{tabular}{cccccc}
\hline $\begin{array}{c}\text { Heater/Cooler } \\
\text { Construction }\end{array}$ & $\begin{array}{c}\text { Heater } \\
\text { Exchange Area } \\
{\left[\mathbf{m}^{2}\right]}\end{array}$ & $\begin{array}{c}\text { Cooler } \\
\text { Exchange Area } \\
{\left[\mathbf{m}^{2}\right]}\end{array}$ & $\begin{array}{c}\text { Regenerator } \\
\text { Effectiveness } \\
{[\%]}\end{array}$ & $\begin{array}{c}\text { Indicated } \\
\text { Efficiency } \\
{[\%]}\end{array}$ & $\begin{array}{c}\text { Indicated } \\
\text { Power }[\text { W] }\end{array}$ \\
\hline $\begin{array}{c}\text { prototype (original, } \\
4 \text { mm tubes) }\end{array}$ & 1.71 & 0.46 & $60 \%$ & 5.5 & 114 \\
Optimized (4 mm tubes) & 1.45 & 1.07 & $60 \%$ & 6.8 & 144 \\
$\begin{array}{c}\text { Optimized } \\
(1 \text { mm tubes) }\end{array}$ & 2.25 & 1.53 & $90 \%$ & 19.5 & 369 \\
\hline
\end{tabular}

\section{Conclusions}

The operating parameters of a prototype alpha type Stirling engine presented in the paper indicate that for a moderate temperature level, increasing charge pressure is only beneficial to a certain level. 
A further increase in charge pressure causes an increase in indicated power, but the efficiency no longer increases. This is happening due to the non-optimal selection of the ratio of heat exchange surface to the dead volume included in heat exchangers. In order to improve the operating parameters of the engine, the adiabatic model has been used. The model was calibrated using experimental data. The calibration has been performed assuming that the average value of the indicated work, for the considered operating points, cannot differ for model and experimental data by more than $1 \%$.

As a result of the calibration, regenerator effectiveness characteristic has been obtained, which was the last missing data in the model. Due to the high uniqueness of the regenerator designs used in prototype solutions, this is a much more accurate method of determining its characteristics than the use of experimental formulas worked out for similar constructions.

It can be concluded that in the tested temperature range, the regenerator effectiveness is not explicitly related to this parameter. In the pressure range above 4 bar it can be seen that the increase in temperature also increases the efficiency, but for pressures below 3 bar the regenerator effectiveness is higher at a temperature of $350{ }^{\circ} \mathrm{C}$ rather than $400{ }^{\circ} \mathrm{C}$. In the case of rising charge pressure a general tendency to increase regenerator effectiveness was observed, regardless of the heating temperature. Finally, it was proposed to use the simplified characteristics of the regenerator effectiveness taking into account the linear relation between charge pressure and regenerator effectiveness.

Simulation tests were carried out while optimizing the heat exchange surface of the heater and regenerator due to the indicated efficiency. The obtained results are therefore a set of optimal design parameters for given operating conditions (heating temperature, charge pressure).

On the basis of the simulation tests carried out using the adiabatic model, it can be stated that the engine power and the indicated efficiency increase with the charge pressure. The indicated power and efficiency also increase with the regenerator effectiveness. This is the result of an increasing amount of heat that is delivered from the regenerator during the expansion process, and thus a reduction of the amount of heat that must be supplied from the outside.

Assuming further development of the regenerator and use of smaller diameter tubes in the heat exchangers, the modified design of the engine has been calculated. This configuration would theoretically increase the indicated efficiency up to $19.5 \%$ (5.5\% prototype) and the indicated power up to $369 \mathrm{~W}$ (114 W prototype).

The results presented in the paper indicate that there is an effective way to use a Stirling engine to generate electricity from the waste heat at moderate temperatures. However, it is necessary to optimize the heat exchange surface and the volume occupied by the working gas in the heat exchangers for the applied heating temperature and charge pressure. The paper presents a new experimental - simulation method enabling the determination of optimal design parameters of a Stirling engine due to the engine efficiency. This method is based on the use of an iterative computational procedure, whose schematic diagram is described in Figure 8. Simulation results compatibility with the experiment, however, depends mainly on the accuracy of the regenerator efficiency estimation, as well as accuracy of the hydraulic resistance estimation. Hence, modelling of the regenerator's efficiency and its hydraulic resistance requires further development. It should be remembered that the requirements set for the regenerator, high efficiency and low hydraulic resistance, are not in line. For example, by increasing the number of elements of the regenerator's filling, the efficiency is rising, while it causes an increase of hydraulic resistance and the dead volume, which have negative impact on the efficiency of the entire Stirling engine.

Author Contributions: Conceptualization, J.K. and M.F.; Data curation, J.K. and M.F.; Formal analysis, J.K. and M.F.; Funding acquisition, J.K.; Investigation, J.K. and M.F.; Methodology, J.K. and M.F.; Resources, J.K.; Software, J.K.; Supervision, J.K.; Validation, J.K. and M.F.; Writing—original draft preparation, J.K. and M.F.; Writing一review and editing, J.K. and M.F. All authors have read and agreed to the published version of the manuscript.

Funding: This research received no external funding.

Conflicts of Interest: The authors declare no conflict of interest. 


\section{Nomenclature}

$\mathrm{A}_{\mathrm{g}} \quad$ heater area of the heat exchange $\left[\mathrm{m}^{2}\right]$,

$\mathrm{A}_{\mathrm{W}} \quad$ cooler area of the heat exchange $\left[\mathrm{m}^{2}\right]$,

$c_{p} \quad$ specific heat capacity of the working fluid at constant pressure $[\mathrm{J} /(\mathrm{kg} \cdot \mathrm{K})]$,

$c_{\mathrm{v}} \quad$ specific heat capacity of the working fluid at constant volume $[\mathrm{J} /(\mathrm{kg} \cdot \mathrm{K})]$,

$\dot{E}_{x} \quad$ rate of increase of the internal energy of the working gas in the space $x[W]$,

$\mathrm{K}_{\mathrm{L}} \quad$ loss coefficient [-],

$\mathrm{m}$ total mass of gas in the engine $[\mathrm{kg}]$,

$\mathrm{m}_{\mathrm{x}} \quad$ mass of the working gas in the space $\mathrm{x}[\mathrm{kg}]$,

$\dot{\mathrm{m}}_{\mathrm{x}} \quad$ mass accumulation speed of the working gas in the space $\mathrm{x}[\mathrm{kg} / \mathrm{s}]$,

$\dot{\mathrm{m}}_{\mathrm{xy}} \quad$ mass flow of the working gas between the spaces $\mathrm{x}$ and $\mathrm{y}[\mathrm{kg} / \mathrm{s}]$,

$\mathrm{n} \quad$ rotational speed of the crankshaft [rev/s],

$\mathrm{p}$ pressure of the working gas $[\mathrm{Pa}]$,

$P_{\text {ind }} \quad$ indicated power of the engine $[W]$,

$\mathrm{p}_{\mathrm{sen}} \quad$ pressure of the working gas measured by the sensor [Pa],

$\mathrm{Q}_{\text {in }} \quad$ energy delivered to the Stirling engine [J],

$Q_{\text {out }} \quad$ energy loss during cooling of the Stirling engine [J],

$\dot{Q}_{x} \quad$ rate of heat transferred into the space $x[W]$,

$\overline{\mathrm{Q}}_{\mathrm{h}} \quad$ average rate of heat delivered to the working gas in the heater [W],

$\overline{\mathrm{Q}}_{\mathrm{k}} \quad$ average rate of heat received from the working gas in the cooler [W],

$\mathrm{R} \quad$ gas constant $[\mathrm{J} /(\mathrm{kg} \cdot \mathrm{K})]$,

Re Reynolds number [-],

$\mathrm{T}_{\mathrm{x}} \quad$ temperature of the working gas in the space $\mathrm{x}[\mathrm{K}]$,

$\mathrm{T}_{\mathrm{xy}}$ temperature of the working gas flowing between the spaces $\mathrm{x}$ and $\mathrm{y}[\mathrm{K}]$,

$\mathrm{T}_{\text {in(out) }}$ temperature of the working gas coming into (out of) the analysed space $[\mathrm{K}]$,

$\mathrm{w} \quad$ instantaneous working gas velocity in the pipeline $[\mathrm{m} / \mathrm{s}]$

W $\quad$ work produced by the Stirling engine [J],

$\mathrm{W}_{\text {ind }}$ indicated work of the engine [J],

$\dot{\mathrm{W}}_{\mathrm{x}} \quad$ rate of work done on the surroundings in the space $\mathrm{x}[\mathrm{W}]$,

$\mathrm{V}_{\mathrm{SC} . \mathrm{c}} \quad$ volume of the compression space swept capacity $\left[\mathrm{m}^{3}\right]$,

$V_{\text {SC.e }} \quad$ volume of the expansion space swept capacity $\left[\mathrm{m}^{3}\right]$,

$V_{\mathrm{x}} \quad$ volume of the space $\mathrm{x}\left[\mathrm{m}^{3}\right]$,

\section{Greek Symbols}

$\alpha \quad$ angle of the phase shift between the spaces of expansion and compression,

$\Delta \mathrm{T}_{\mathrm{r}} \quad$ regenerator temperature difference,

$\Delta \mathrm{V}_{\mathrm{c}} \quad$ change of volume in the compression cylinder,

$\Delta \mathrm{V}_{\mathrm{e}} \quad$ change of volume in the expansion cylinder,

$\varepsilon \quad$ regenerator effectiveness,

$\eta^{\text {net }}{ }_{a}$ net adiabatic efficiency of the Stirling engine,

$\phi \quad$ angle of rotation of the crankshaft shaft with respect to the cylinder of the expansion space,

K isentropic exponent,

$\tau_{c}$ time of the cycle,

\section{Subscripts}

ad adiabatic,

c compression space,

ch charge pressure,

e expansion space,

g gas supplying the heat to the engine,

$\mathrm{h}$ heater, 


$\begin{array}{ll}\mathrm{k} & \text { cooler, } \\ \text { pump } & \text { work pumping } \\ \mathrm{r} & \text { regenerator, } \\ \mathrm{W} & \text { cooling water }\end{array}$

\section{References}

1. Invernizzi, C.M.; Ahmed Sheikh, N. High-efficiency small-scale combined heat and power organic binary Rankine cycles. Energies 2018, 11, 994. [CrossRef]

2. Ziabasharhagh, M.; Mahmoodi, M. Numerical solution of beta-type Stirling engine by optimizing heat regenerator for increasing output power and efficiency Numerical Solution of Beta-type Stirling Engine by Optimizing Heat Regenerator for Increasing Output Power and Efficiency. J. Basic Appl. Sci. Res. 2016, 22, 1395-1406.

3. Idroas, M.Y.; Farid, N.A.; Zainal, Z.A.; Noriman, K.; Azman, M. Mechanical power assessment of an alpha V-type stirling engine converted diesel engine. Int. J. Mech. Mater. Eng. 2011, 6, 160-166.

4. Petrescu, S.; Costea, M.; Harman, C.; Florea, T. Application of the Direct Method to irreversible Stirling cycles with finite speed. Int. J. Energy Res. 2002, 26, 589-609. [CrossRef]

5. Finkelstein, T.; Organ, A.J. Air Engines: The History, Science and Reality of the Perfect Engine; American Society of Mechanical Engineers: Fairfield, CT, USA; ASME Press: New York, NY, USA, 2009; ISBN 9780791801710.

6. Buoro, D.; Casisi, M.; Pinamonti, P.; Reini, M. Optimal synthesis and operation of advanced energy supply systems for standard and domotic home. Energy Convers. Manag. 2012, 60, 96-105. [CrossRef]

7. Thomas, B. Benchmark testing of Micro-CHP units. Appl. Therm. Eng. 2008, 28, 2049-2054. [CrossRef]

8. Kropiwnicki, J. Design and applications of modern Stirling engines. Combust. Engines 2013, 243-249.

9. Kropiwnicki, J. Analysis of start energy of Stirling engine type alpha. Arch. Thermodyn. 2019, 40, $243-259$.

10. Kropiwnicki, J.; Szewczyk, A. Stirling Engines Powered by Renewable Energy Sources. Appl. Mech. Mater. 2016, 831, 263-269. [CrossRef]

11. Valenti, G.; Silva, P.; Fergnani, N.; Di Marcoberardino, G.; Campanari, S.; Macchi, E. Experimental and numerical study of a micro-cogeneration Stirling engine for residential applications. Energy Procedia 2014, 45, 1235-1244. [CrossRef]

12. Lane, N.; Beale, W. A biomass-fired $1 \mathrm{kWe}$ Stirling engine generator and its applications in South Africa. In Proceedings of the 9th International Stirling Engine Conference, Johannesburg, South Africa, 2-4 June 1999.

13. Cheng, C.H.; Yang, H.S.; Keong, L. Theoretical and experimental study of a 300-W beta-type Stirling engine. Energy 2013, 59, 590-599. [CrossRef]

14. Gheith, R.; Aloui, F.; Tazerout, M.; Ben Nasrallah, S. Experimental investigations of a gamma Stirling engine. Int. J. Energy Res. 2012, 36, 1175-1182. [CrossRef]

15. Karabulut, H.; Yücesu, H.S.; Çinar, C.; Aksoy, F. An experimental study on the development of a $\beta$-type Stirling engine for low and moderate temperature heat sources. Appl. Energy 2009, 86, 68-73. [CrossRef]

16. Kongtragool, B.; Wongwises, S. Performance of low-temperature differential Stirling engines. Renew. Energy 2007, 32, 547-566. [CrossRef]

17. Li, T.; Tang, D.; Li, Z.; Du, J.; Zhou, T.; Jia, Y. Development and test of a Stirling engine driven by waste gases for the micro-CHP system. Appl. Therm. Eng. 2012, 33-34, 119-123. [CrossRef]

18. Sripakagorn, A.; Srikam, C. Design and performance of a moderate temperature difference Stirling engine. Renew. Energy 2011, 36, 1728-1733. [CrossRef]

19. Qian, X.; Lee, S.; Chandrasekaran, R.; Yang, Y.; Caballes, M.; Alamu, O.; Chen, G. Electricity evaluation and emission characteristics of poultry litter co-combustion process. Appl. Sci. 2019, 9, 4116. [CrossRef]

20. Sowale, A.; Kolios, A.J.; Fidalgo, B.; Somorin, T.; Parker, A.; Williams, L.; Collins, M.; McAdam, E.; Tyrrel, S. Thermodynamic analysis of a gamma type Stirling engine in an energy recovery system. Energy Convers. Manag. 2018, 165, 528-540. [CrossRef]

21. Tlili, I.; Timoumi, Y.; Nasrallah, S. Ben Analysis and design consideration of mean temperature differential Stirling engine for solar application. Renew. Energy 2008, 33, 1911-1921. [CrossRef]

22. Bataineh, K.M. Numerical thermodynamic model of alpha-type Stirling engine. Case Stud. Therm. Eng. 2018, 12, 104-116. [CrossRef] 
23. García, M.T.; Trujillo, E.C.; Godiño, J.A.V.; Martínez, D.S. Thermodynamic model for performance analysis of a Stirling engine prototype. Energies 2018, 11, 2655. [CrossRef]

24. Organ, A.J. The Regenerator and the Stirling Engine; Mechanical Engineering Publications: London, UK, 1997; ISBN 1860580106.

25. Furmanek, M.; Kropiwnicki, J. Hydraulic resistance analyses of selected elements of the prototype Stirling engine. Arch. Thermodyn. 2019, 40, 123-136.

26. Mou, J.; Hong, G. Startup mechanism and power distribution of free piston Stirling engine. Energy 2017, 123, 655-663. [CrossRef]

27. Tavakolpour-Saleh, A.R.; Zare, S.H.; Bahreman, H. A novel active free piston Stirling engine: Modeling, development, and experiment. Appl. Energy 2017, 199, 400-415. [CrossRef]

28. Kwankaomeng, S.; Silpsakoolsook, B.; Savangvong, P. Investigation on stability and performance of a free-piston Stirling engine. Energy Procedia 2014, 52, 598-609. [CrossRef]

29. Kropiwnicki, J. Application of Stirling Engine Type Alpha Powered by the Recovery Energy on Vessels. Pol. Marit. Res. 2020, 27, 96-106.

30. Ranieri, S.; Prado, G.A.O.; MacDonald, B.D. Efficiency reduction in stirling engines resulting from sinusoidal motion. Energies 2018, 11, 2887. [CrossRef]

31. Chmielewski, A.; Gumiński, R.; Mączak, J. Analysis of isothermal thermodynamic processes in the Stirling engine. Proc. Inst. Veh. 2016, 2/106, 13-20.

32. Kamen, D.; Langenfeld, C.C.; Bhat, P.; Smith, S.B. Stirling Cycle Machine. Available online: https: //www.google.com/patents/US8474256 (accessed on 12 May 2019).

33. Wrona, J.; Prymon, M. Mathematical Modeling of the Stirling Engine. Procedia Eng. 2016, 157, 349-356.

34. Thombare, D.G.; Verma, S.K. Technological development in the Stirling cycle engines. Renew. Sustain. Energy Rev. 2008, 12, 1-38. [CrossRef]

35. Cichy, M.; Kneba, Z.; Kropiwnicki, J. Causality in Models of Thermal Processes in Ship Engine Rooms with the Use of Bond Graph (BG) Method. Pol. Marit. Res. 2017, 24, 32-37. [CrossRef]

36. Cichy, M.; Kropiwnicki, J.; Kneba, Z. A Model of Thermal Energy Storage According to the Convention of Bond Graphs (Bg) and State Equations (Se). Pol. Marit. Res. 2015, 22, 41-47. [CrossRef]

37. Babaelahi, M.; Sayyaadi, H. Modified PSVL: A second order model for thermal simulation of Stirling engines based on convective-polytropic heat transfer of working spaces. Appl. Therm. Eng. 2015, 85, 340-355. [CrossRef]

38. Kahaleras, M.; Lanzetta, F.; Layes, G.; Nika, P. Friction Factor and Regenerator Effectiveness in An Oscillating Gas Flow. In Proceedings of the 5th Internantional conference on Heat Transfer and Fluid Flow in Microscale, Marseille, France, 22-26 April 2014. 